\title{
A Double Helix Metaphor for Use and Usefulness in Informing Systems
}

\author{
Peter Bednar, School of Computing, \\ University of Portsmouth, UK; \\ Department of Informatics, Lund University, Sweden
}

\author{
Christine Welch, Department of Strategy and \\ Business Systems, University of Portsmouth, UK
}

\section{peter.bednar@ics.lu.se christine.welch@port.ac.uk}

\begin{abstract}
Following the theme of this monograph, this paper discusses a dialectic we perceive to subsist between meaningful use and reflection upon use. This dialectic between experiencing use and reflecting upon experiencing use (or thinking, and thinking about thinking) may be considered in the following way. Each of these elements is subject to change. As reflection triggers change in use, and such change triggers further reflection, a spiral comes about. Lived human experience, and reflection upon that experience, seems to shape a double helix. In this paper, the authors suggest a need for a hermeneutically-informed, phenomenological approach when considering the complexities of informing systems, viewed as human activity systems. It is suggested that human actors, as users of informing systems, must own and control any inquiry into use in relation to design for themselves, and that individual sensemaking processes are the key to successful interaction within the double helix metaphor.
\end{abstract}

Keywords: Use, Usefulness, Informing Systems, Phenomenology, HermeneuticsDouble Helix.

\footnotetext{
Material published as part of this publication, either on-line or in print, is copyrighted by the Informing Science Institute. Permission to make digital or paper copy of part or all of these works for personal or classroom use is granted without fee provided that the copies are not made or distributed for profit or commercial advantage AND that copies 1) bear this notice in full and 2) give the full citation on the first page. It is permissible to abstract these works so long as credit is given. To copy in all other cases or to republish or to post on a server or to redistribute to lists requires specific permission and payment of a fee. Contact

Publisher@InformingScience.org to request redistribution permission.
} 


\section{Introduction}

"...human history is a two stranded rope; the history of events and the history of ideas develop in intimate relation with each other yet each according to its own logic and its own time scale; and each conditions both its own future and the future of the other." (Vickers, 1965, p.15)

The theme of this monograph is a dialectic we perceive to subsist between meaningful use and reflection upon use in informing systems (using a metaphor of double helix, as shown in Figure 1). We are by no means the first to reflect upon such relationships in a wider context (see, for example, Vickers, 1965, quoted above). In this paper, we explore the nature of the symbiosis between experiences people have in using systems to inform themselves (or others) and the evolution of these informing systems. If we choose a metaphor of a two stranded rope, we can see that the coil of one strand influences the coil of the other in an ongoing helix - neither can remain straight without challenging the integrity of the rope. Vickers refers to 'history'. In this paper, we use this term to denote on-going and continuous change of experience, and development of experience (i.e. process of 'experiencing'), by both individuals and collective groups. The rope metaphor reflects our thinking that human behavior unfolds in a continuous pattern of response to reflection upon experience. As conscious beings, we have no choice but to reflect and thus our consciousness changes from one moment to the next. Börje Langefors highlights the on-going nature of human sense-making processes in his Infological Equation (Langefors, 1966). Our interpretations of perceptions are related to assumptions arising from previous reflections upon our lived experiences. It is, of course, possible for individuals to become entrapped in taken-for-granted assumptions. We will discuss these issues further in a later section of the

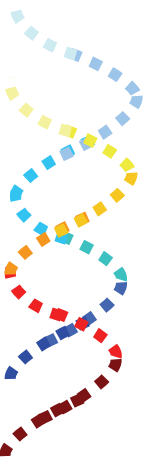

Figure 1: Double Helix paper. 
Few people would dispute that a dialectic subsists between users' experiences of ICT artifacts and the processes of design and redesign. For example, we may consider the recent launch of the iPhone by the Apple Corporation. Undoubtedly, this has been preceded by discussions between designers, and users of cell phones and MP3 music players, to discover which features of these devices might be popular if incorporated into a new artifact. Further testing of devices by prospective users will also have taken place in order to refine design and enhance product development. A great deal of academic debate has taken place in the past around this dialectic relationship. See, for example, discussions by Bijker, Hughes, \& Pinch (1987) and Mackay (1995) in which they debate evidence for technological determinism of social use, as against social shaping of technologies.

However, the authors believe that processes involved in development of what are usually termed 'information systems' must be distinct from those concerned with artifact design. Information (informing) systems may be considered to have a twofold purpose: to support people in informing themselves, and/or to support people in helping others to inform themselves. Research into processes for developing informing systems may be seen as a quest for approaches which combine rigor with appropriate recognition of complexity, and which address meaningfulness of systems from the perspectives of individual participants. We consider that a key to achieving this balance of rigor with relevance lies in creation of an effective learning spiral in which stakeholders (i.e. actors who participate in using informing systems) can engage in reflection within the context of their use. How could this be done? The authors point to two approaches which support application of hermeneutically-informed, phenomenological inquiry into human activity systems in practice.

The next section of the paper gives the philosophical background and ideas underpinning the discussion. Following this, the authors consider concepts of use, usability and usefulness in relation to the double helix metaphor. A further section then gives two examples of practical application. Finally, we attempt to draw some conclusions.

\section{Philosophical Perspectives}

A key aspect of meaningful research in this area, for the authors, is consideration of individual and collective sense-making processes (Dervin, 1983; Weick, 1995). The authors reject a realist approach, 
which assumes that there is one world 'out there' awaiting individual discovery. Alfred Schutz, writing of the work of Edmund Husserl (1954/1970), puts forward an argument for phenomenological approaches as follows:

'All empirical sciences refer to the world as pre-given; but they and their instruments are themselves elements of this world. Only a philosophical doubt cast upon the implicit presuppositions of all our habitual thinking - scientific or not - can guarantee the "exactitude" not only of such a philosophical attempt itself but of all the sciences dealing directly or indirectly with our experiences of the world ...' (Wagner, 1970, p.54).

It is this 'philosophical doubt' that we pursue when we adopt a hermeneutic approach. Thus, for the authors, a kind of critical idealism may be preferred over realism. We recognize that individuals create their own perspectives of 'realities', through sense-making (see Berger \& Luckmann, 1967; Radnitzky, 1970). For the authors, a kind of critical idealism may be preferred over realism, and thus sharing of 'realities' is problematic. The way forward is a communicative effort, applying critically-informed systemic thinking, drawing on Gregory Bateson's holistic, hermeneutic approach (Bateson, 1972). The focus is on selfemancipation through systemic meta-reflection from unique individual perspectives of autonomous and self-reflecting systems. Bateson proposes a perspective of human self-awareness and understanding.

The authors believe that theory and practice are indivisible, neither can progress without the other and they stand in a dialectic relationship. What Radnitzky (1970) calls Continental or hermeneutic-dialectic (HD) schools of metascience share this position. Whereas, according to Radnitzky, Anglo-Saxon or logical-empirical (LE) schools strictly separate theory from practice. Moreover, HD schools of metascience acknowledge the importance of history, which LE schools tend to ignore. In this context, we are not referring to history as a recorded sequence of past events, but as an on-going, continuous process of change in predefined variables (Langefors, 1966). The authors acknowledge that approaches based in Hermeneutic Dialectics recognize, not only individual uniqueness, but a need to avoid a Cartesian split in analysis. Any observation must be made by a particular observer, under particular circumstances, in a particular context (Maturana \& Varela, 1992). It is not possible to separate observers from what is observed, in order to objectify/simplify analysis. Inquiries based in an LE tradition are likely to give great attention to precision and clarity in expressing a problem 
situation. Radnitzky (1970) points to a danger within such inquiries that an artificial separation may arise between observations made and the unique perspectives of observer and observed. Adopting such a focus of attention could consequently lead to a loss of critical awareness and entrapment in confusion between specific and generalizable descriptions of experiences. Researchers whose inquiries are based in philosophical practice from an HD tradition, on the other hand, are likely to make explicit recognition of uncertainty/ambiguity as features of socially-constructed perspectives on human activity. Their focus is likely to be on transparency, rather than clarity, emphasizing individual selfawareness.

Individual learning may be described as taking place through sensemaking processes as a response to messy and uncertain contexts in which resolutions are sought. Different orders of learning may be identified, based on a cycle of experience and reflection on experience (Argyris \& Schon, 1974; Bateson, 1972). Higher orders of learning may involve reflection on sense-making processes themselves, i.e. a learning cycle may become transformed into a spiral. It is possible to describe reflection on sense-making as an exercise in practical philosophy, or exercise of the kind of 'philosophical doubt' described by Schutz (Wagner, 1970). The authors believe that certain points follow from this. First, if individual learning is a creative process based in sense-making, then context is clearly important. Any unique individual's view is based in reflection on experience (Bateson, 1972), and experience is context specific. It is suggested in this work, therefore, that an examination of contextual dependencies, as part of analysis, will be important. The Infological Equation (Langefors, 1966) suggests that individuals develop unique understandings (meanings) by examining data in the light of pre-knowledge gained from reflecting on experiencing during a previous time interval. Furthermore, processes of reconstructing new understandings (meaning-shaping), by examining data in light of experience, may be what constitute organizations, their goals and cultures.

Many researchers interested in informing systems 'design' have attempted to explore philosophical frameworks based in phenomenology (e.g. Klein, 2006; Mumford, 2003). These researchers recognized that they were dealing with autonomous human beings, who also attempted to make sense of their worlds. However, in order to take into account unique individual sense-making processes within an organizational problem arena, we suggest a need for analysts to explore multiple levels of 
contextual dependencies. Since it is not possible to explore a problem space from someone else's point of view, it follows that an external analyst/designer can only play a supportive role in enabling individuals within a given context to explore their own sense-making.

In the authors' view, exploration of multiple levels of contextual dependency may help to avoid entrapment in various types of reductionism: sociological, psychological or technological. It may also help to eliminate tendencies towards generalization, or substitution of an external analyst's own views for those of the participating stakeholders. Furthermore, we advocate attempts to go beyond grounding of research in phenomenological paradigms, recognizing a need for critically-informed understandings of problem-spaces. The authors suggest that, in order to avoid various types of reductionism and introduce 'philosophical doubt', analysts might attempt to incorporate philosophy as an integral part of their research practice (Bateson, 1972; Hirschheim, Klein, \& Lyytinen, 1995).

A reductionist approach, emphasizing artifact design, ignores the possibility of emergent properties, which appear when individual behavior is considered in the context of systems. It is important to note that recognition of emergent properties of a system as a whole is insufficient. An individual actor acting within the context of a human activity system (of which an informing system may be viewed as one special case) may represent emergence of a different order. It is possible that the emergent properties associated with that individual may amount to more than those of the system as a whole, when considering the influence of other systems of which s/he is a component. For example, consider a fashion house as a human activity system. We might view a couturier as one contributing component, if we choose to draw a boundary around a 'system for supplying ladies clothing'. However, considered as a 'system for making profits by attracting customers to buy designer fashion wear', the emergent properties change, as the identity and reputation of the designer becomes an attracting influence (Bednar, 2001). As pointed out by Werner Ulrich in his discussion of boundary critique, perception of a system varies with the stance of the observer (Ulrich, 2001).

In some theories of sense-making attempts are made to differentiate between an observer's and another actor's pictures of 'reality'. See, for example, work by Dervin (1983). These views are not assumed to be complete or static. Instead, they are characterized by discontinuities. 
Individuals make efforts to bridge these gaps in a continual process of meaning-shaping. 'Information' might here be described as a sensemaking/meaning-shaping continuity (re)constructed by a particular individual at a particular moment in time and space, through continual adjustments of perspective. Any observer must attempt to shape meaning in a particular situation by comparing different actors' apparent perspectives within given criteria, i.e. by carrying out a 'circling of realities'. Thus, anyone wishing to inquire into informing system use must continually align themselves with an actor's perspective. For example, the meaning shaping in a particular situation can be described through a comparison of different actors' perspectives within given structural criteria. When we speak of 'circling of realities', we refer to a necessity to acquire a number of different perspectives (in time-space) needed to get a better and more stable picture of a particular actor's view of 'reality'. This actor's view of 'reality' is influenced by reflecting on interactions with other actors (Bateson, 1972). It is most important that those considering systems design recognize that they are setting up personal boundaries for a situation by defining it from their own experiences and preferences. We all have a pre-understanding of something, which is influenced by our own values, wishful thinking, and how we as individuals have been socialized into a particular society. Awareness of this process, and attempts to focus upon the understandings and perspectives of the actors/stakeholders, are needed in shaping the requirements for design.

The claim to take an actor perspective might seem to be unreasonable, but with the help of what is known as the 'hermeneutic circle', the preunderstanding is being reviewed gradually, with the support of ones experience. In other words there is a continual exchange/interchange between an individual's pre-understanding and experience, and it is within this process that inquiry may progress (Thurén, 1991). Furthermore, a dialectic emerges in such interactions, because each individual is concurrently interacting with others (Hermeneutic Dialectics). HansErik Nissen draws attention to human perception of time (Nissen, in this monograph). He points out that on some occasions individuals see time as a linear progression from past to future. In other circumstances, however, individuals perceive time as a cyclical flow. For example we might consider the lifecycle of a frog. Frogs spawn in the spring; tadpoles hatch and grow into new frogs during the summer. These frogs either perish or grow strong during the year. In the winter, they shelter at the bottom of a pond, waiting for a chance to mate next spring, pro- 
ducing spawn. But we know that this is not the same spawn as before; it is the beginning of a new generation. Thus, it is not a life cycle but a spiral. We perceive a helix to form as a metaphor which combines both views of time.

The term 'sense-making' is intended to suggest the idea that people constantly meet gaps in meaning which need to be overcome. People move through life moment-by-moment, step-by-step, by experiencing. A step can be a re-occurrence of previous behaviors but, philosophically speaking, it is always a new step since it takes place in a new moment in time and space. Sense-making relates to that moment when a step in movement is halted and hindered because of all the discontinuities that surround us. We can reflect, like Heraclitus, "No man ever steps in the same river twice, for it is not the same river and he is not the same man." This aspect of human experiencing creates a need to construct new meanings and understandings. In the context of our double-helix metaphor, users and designers must unravel how an individual interprets and overcomes this moment. Why was a gap experienced? How did the individual move strategically or tactically to overcome the gap? How did the individual continue her/his journey after the bridge building (Dervin, 1989)?

\section{Thinking about Use}

Different researchers have conceptualized the term 'information system' in a variety of ways. Nissen (1984), for example, points out that information systems have two distinct dimensions, i.e. they usually include information technology and they are associated with people capable of acting as self-steering systems. Checkland and Holwell (1998) make a similar point, suggesting that not one, but two systems are involved - a system to be served (i.e. people engaged in activities), and a serving system containing elements which generate data useful to those people. Sauer also points out that an information system is not just an artifact, but that: 'Economic task, organizational, buman relations / labor process and technical perspectives are all involved' (Sauer, 1993, p 10). Claudio Ciborra (2002), points to a tendency within the field of information systems research to adopt perspectives suggested to be associated with outdated perspectives of natural sciences, which researchers proclaim to be 'objective.' Thus, systems professionals may be observing social phenomena and yet insist upon recording their observations using abstractions such as entity-relationship diagrams in order to preserve 'ob- 
jectivity'. As Ciborra puts it: "Thus, one tends to forget ... the role of human choice bebind the technical artefacts, and study the user side of IS by adopting the methods of natural sciences."

The authors of this paper wish to highlight the confusion inherent in treating technical and social domains as if they are either alike or susceptible to 'objective' investigation. Furthermore, we believe use of the term 'information system' itself to be problematic, since it suggests that there is a commodity 'information' which can be readily transmitted from one person to another. Since human beings are required to take part in such a system in order to interpret data and transform it into something meaningful to them, we consider it preferable to refer to a system by which a person seeks to inform herself / himself as a selfinforming system. Similarly, a system through which a person seeks to support others in informing themselves might be called an informing system.

Drawing on work such as Mumford, Hirshheim, Fitzgerald, and WoodHarper (1984) and Checkland and Holwell (1998), it appears to the authors that the question 'What is the purpose of an informing system?' is a relevant one to ask. Design of (i.e. human efforts to purposefully influence change or transformation of) an informing system, which is to be assessed as meaningful from someone's perspective, requires understanding (a process of meaning-shaping) as to what would make it meaningful for that person. However, if people are regarded as essential elements within an informing system, as the definitions above must imply, then a further dimension of complexity is added. People cannot be the subject of design by external professional developers. It may be possible only to contemplate design of use of an informing system (process), but not of the system itself. Borje Langefors (1966) pointed out in his Infological Equation that each individual creates meaningful information for himself. The equation " $\mathrm{I}=\mathrm{i}(\mathrm{D}, \mathrm{S}, \mathrm{t})$ " shows how meaningful information (I) may be constructed from the data (D) in the light of participants' pre-knowledge (S) by an interpretive process (i) during the time interval (t). The necessary pre-knowledge (s) is generated through the entire previous life experience of the individual. This can be viewed as a single helix of experiencing, interpreting and reflecting, because understanding is continually changing as time goes by. We might consider that this reflects Heidegger's words, that objectivity has meaning only for a subject who judges. It follows then that understanding of use is a matter of interpreting by the individual user concerned, 
through her sense-making processes. We would argue, therefore, that those individuals must own and control the process of development for themselves and cannot delegate such tasks entirely to an external professional 'designer'.

A key purpose for design of systems appears to be to change something for the better, as defined by some participant in, or observer of, that system. Such change may be seen as an emergent consequence from combined individual and organizational learning and sense-making processes (Bednar \& Welch, 2005). In order for beneficial change to be brought about, both explicit and tacit organizational norms must be challenged. This requires users of ICT's and actors in organizational processes, both individually and collectively, to contemplate embracing the (as yet) unknown (Bednar \& Mallalieu, 2001). Design efforts are contemplating a future problem space without any guarantee of success. Such challenges are often found to be uncomfortable by some participants in organizational life (see, e.g. Argyris, 1990; Mumford, 2003; Walsham, 1993) and thus a political dimension adds further complexity.

We do not intend, in this paper, to define human beings by their use of a technology or process. 'User' should not be perceived as referring to people as important mainly in their role in using ICT artifacts. We prefer to write about 'workers' or to use examples of names of people in their proper professions, when talking about people who use IT artifacts. This helps to break an unfortunate linguistic trend. On those occasions when we refer to 'users' we do not intend to imply assumptions of common characteristics between collections of individual people who are 'users' of particular technologies.

People, as users, interact with ingenious creations of designers in the course of daily life. Each user's experience of use is unique and contextual. Descriptions of people's experiences as users may be made either by themselves or by other observers of use, e.g. analysts (formally or informally). As use is experienced, so descriptions of use will be interpreted by users and other analysts. Such interpretations will, in turn, lead to change in the experiences themselves in an unfolding process over time, e.g. the experience of driving a car for the first time cannot be repeated. The second drive is a different experience, influenced by interpretation of experiencing the first. Thus, experiencing use can be seen as a spiral, driven on by the interaction of experiencing and interpreting of experience (see Figures 2 and 3). 
Living, experiencing and reflecting, individually and in various groups we perceive as on-going processes. This we have tried to indicate by the directed arcs suggesting a helix. The diagram shows two interacting helices, which may be described in the following way:

1. Helix one: Living and experiencing. This helix relates technological system use and design. End users meet, use and experience systems and their designers. Systems analysts / developers design and redesign systems and infrastructures and meet end users.

2. Helix two: Reflecting about system use and design individually, as well as communicating and reflecting both in peer groups and in mixed groups.

We perceive each helix to influence the other. Thinking about use triggers interpretation of the descriptions of experiences made by users and

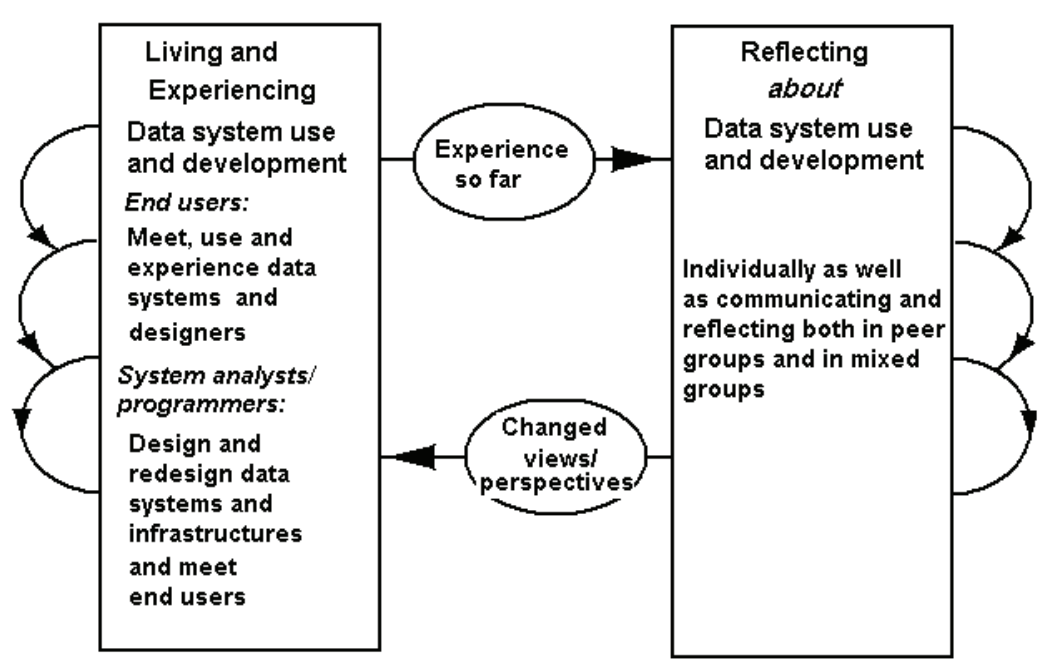

\section{Figure 2: Experiencing and Reflecting}

other observers. Such interpretations trigger changes in experience of use and may lead to novel approaches to use, triggering ideas for further ingenuity in design. 


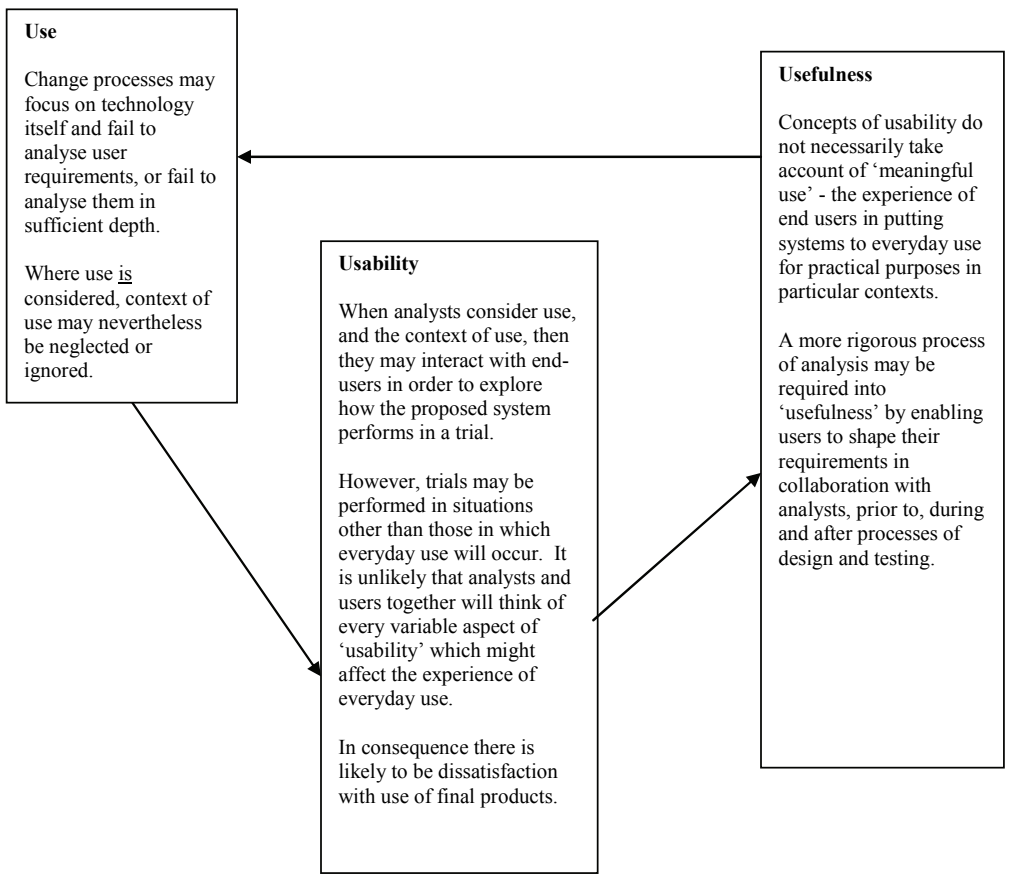

Figure 3: Experiencing use.

Ingenious designers create new technologies aiming to satisfy the requirements of particular use. Such creative thinking begins a spiral in which reflections on use (by users and analysts interacting with them) can lead to modifications in design by focusing on usability (can an artifact satisfy the requirements of use?). Further reflections on usefulness (could the requirements of users be better satisfied than they are?) drive the spiral on by triggering further ingenuity in design. See Figure 3 for an overview of the relation between use, usability and usefulness.

In the context of informing systems, 'Use' reflects a purpose for the system (what someone wanted to achieve with it). Designers and developers will have a view of this purpose when they begin an intentional process of creative development. Reflecting upon this purpose as development progresses may lead developers (and/or other participants in the creative process) to consider 'usability' (bow can the users be supported to pursue that purpose effectively / easily / pleasantly?) 
Here, we can consider Gregory Bateson's (1972) concept of multiple orders of learning. At lower orders, an individual attempts to make sense of phenomena in order to bridge an epistemic gap. Higher orders of learning occur when the individual reflects upon his own sensemaking processes in this context, and upon these reflections themselves. We might see a focus on purpose (what) as an instance of what Bateson refers to as zero order learning, whilst reflection upon usability (how) may suggest a move to first order, i.e. involving reflection upon the process by which the what is achieved.

However, this does not appear to go far enough. Bateson refers to informing as creation of a 'difference that makes a difference.' Our purpose in highlighting these three terms is to focus upon cognition. In order to cognize, we must be able to recognize a phenomenon, i.e. to perceive a difference. Each individual who seeks to make use of an informing system has reasons of her own for doing so, which are both unique and contextual. It is this that we refer to when we use the term 'usefulness' - not what, or how, but why does the individual engage as a participant in the informing system? This is the difference that makes a difference for her.

Unless designers reflect upon 'usefulness' (why and from whose perspective?), it is likely that their creative process may focus upon a different problem space than that which is of genuine concern to problem owners (intended 'users'). Consider, for example, a number of well-publicized cases of organizational ICT developments that have failed to deliver the benefits expected from them. In some cases, participants within organizations have reflected that problems arose through conception of the development process as occupying a technological or socio-technical problem space, ignoring cultural dimensions. A shift of perspective on the nature of the problem space has sometimes enabled 'success' to become achievable.

As Heidegger (1962) points out, experience of living can lead in many different, unexpected directions that cannot be planned or managed in advance. It follows that any process of design that focuses only on specific purposes (what and how) is unlikely to be experienced as satisfying by intended 'users' of the system. In work related to application of formal methods, Claudio Ciborra points out two alternative strategies which developers of an informing system could choose to adopt. 
When faced with a novel problem space, a person might first try to make sense of it in a context of her previous experiences in seeking for resolutions. Beginning within familiar competences, and gradually 'tinkering' and moving outwards from this base, she might only turn to wider or more formal sources of unfamiliar 'knowledge' if her existing competences prove insufficient to the task (see Ciborra, 1992). This first type of strategy, Ciborra refers to as bricolage, or improvisation. Similar observations can be recognized in the work of Ehn (1993) related to efforts of going beyond Participatory Design. Ciborra relates the concept of improvisation to the complex world of open source, and how the phenomena of open source as a community has been able to deal with increasingly complex and dynamic software development, through 'hacking'. This may be contrasted with commonly specified purposes behind more formal information systems methodologies, which assume orchestrated efforts in 'information systems' analysis and development.

We can reflect that hermeneutically-informed, phenomenological approaches to analysis are a necessary part of the double helix described earlier. In a method for contextual inquiry, such as the Strategic Systemic Thinking framework (Bednar, 2000), we can see a multitude of different roles for users (and other actors) as analysts. They may make descriptions of their own sense-making and experiencing, and reflect upon them. The external analyst (e.g. consultant), on the other hand, both observes her/his own experiencing and assists users (or other actors) in making their descriptions and interpretations. Figures 2 and 3 draw attention to the thinking / reflecting about use side and presents different dilemmas of system analysis/design as against system use.

\section{Double Helix}

As we have seen, Gregory Bateson (1972) put forward a concept of multiple orders of learning. At lower orders, an individual attempts to make sense of phenomena in order to bridge an epistemic gap. Higher orders of learning occur when the individual reflects upon his own sense-making processes in this context, and upon these reflections themselves. We might again consider this to involve the creation of a double helix. Zero and first order of learning we relate to the 'first' helix. The second order of learning we see related to the second helix. When Bateson remarks on his description of order he suggest that 'the talking and thinking about' the second order, in its own right, would be 
outside of the taxonomy. In a sense it would be 'parallel' to it or possibly something which could be described as order 2.5.

When referring to the metaphor of double helix, we could imagine that when we, as observers, discuss the double helix (as a metaphorical phenomenon) we might do it from a perspective within a 'third' external helix. We might reflect with Gregory Bateson that there is a double bind in our thinking which relates to the double helix theme. As conscious human beings, we have no choice but to reflect (see Figure 4). Bateson suggests that efforts to adopt a third party perspective (an imaginary outsider parallel) may help to break out of double bind, i.e. in our view an observer perspective brings out creation of a triple helix.

Werner Ulrich $(2001,2006)$ discusses research as a means to promote reflective societal practice $\mathrm{He}$ points to three indispensable qualities for reflective competence (in relation to one's own claims and those of

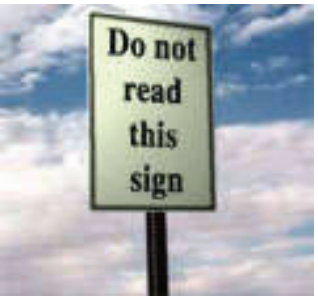

Figure 4: Example of Double Bind (Hay, 2001) others). It must be:

1. self-critical: the effort of systematically examining one's own premises through self-reflection and dialogue, with a view to carefully qualifying the meaning and validity of one's claims;

2. emancipatory: working actively to help others in emancipating themselves from one's claims, as well as from theirs; and

3. ethically alert: making transparent to oneself and to others the value implications of one's claims, and limiting these claims accordingly (Ulrich, 2006, p16).

To us, Ulrich's three qualities described above reflect the same characteristics of critical systemic thinking that we recognize in the work of Gregory Bateson, i.e. a focus on self-emancipation through systemic meta-reflection from unique individual perspectives of autonomous and self-reflecting systems.

The question for us all to address is how we should conduct hermeneutically-informed, phenomenological inquiry into human activity systems in a practical setting. We discuss some examples of approaches 
which attempt to do this, below. The first of these relates to the specific context of professional practice in systems analysis. Here the focus is on inquiry into complex problem spaces in an organizational setting (e.g. ICT development as an instance of organizational change). The second example focuses on image as a therapeutic catalyst in the context of dysfunctional relationships within human activity systems.

The Strategic Systemic Framework (see Figure 5) is an example of an approach to contextual inquiry that may be helpful in empowering individuals to break out from prejudices and explore their own perspectives in order to escape from a double bind (e.g. Bednar, 2000).

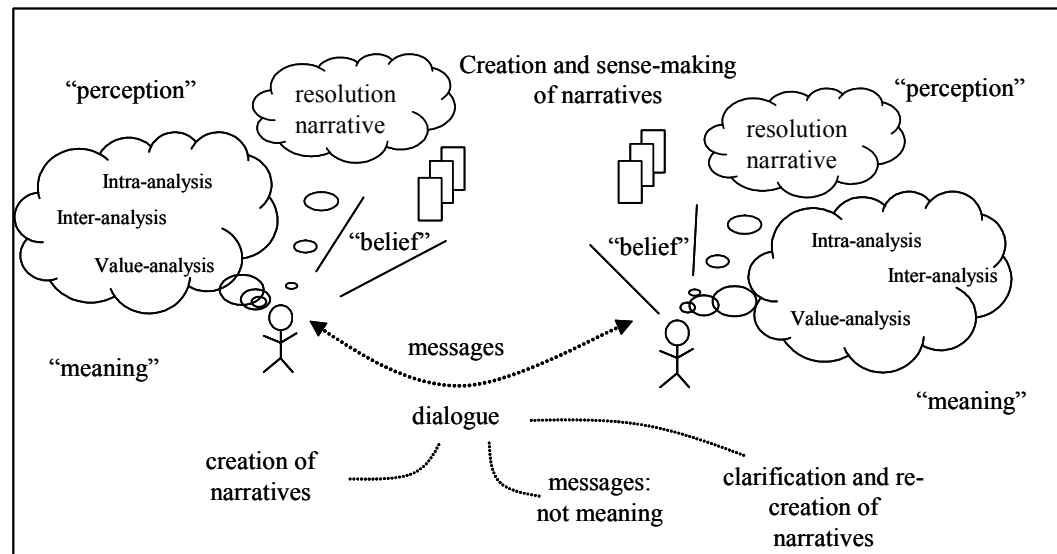

Figure 5: Sense-making in the SST framework

The process of the SST framework includes three, interrelated aspects (intra-analysis; inter-analysis and value analysis). All aspects incorporate tools and techniques that support actors, both in the process of elaboration and in the process of categorization of messages.

The intra-analysis aspect is intended to support creation of a learning spiral, as actors are supported to reflect and think about a problem space with this collection of tools and techniques. In inter-analysis, actors are supported in creating a learning spiral that focuses on communication of their individually-created narratives, and sense-making of others' individually-created narratives. In value analysis, actors are supported, both individually and in group interaction, to create a learning spiral that focuses on reflecting and thinking about the scale of 'measurement'. What is worthwhile as a scale of comparison for evaluation of narratives, and assessing how they will be evaluated? 
All three aspects together are intended to support people in creating a frame of reference for reflection over their process of inquiry. Each aspect may be described using the metaphor of a helix; and together they 'form' an intertwined, double helix upon which participants may reflect.

Another approach supporting individuals to break out from entrapment of mind can be found in the work of Hay $(2001,2007)$, relating to image as a therapeutic catalyst. Here, she uses visualization of an outside perspective to support individuals caught in a double bind in e.g. dysfunctional family relationships through games using computer animation. It reflects Gregory Bateson's idea of an "Infinite dance of changing coalitions" (Bateson, 1972, pp. 240-242), which is itself a translation of Von Neumann and Morgenstern's game theory.

Human sense-making is the essence of the creative dialectic in the helices to which we refer. We reflect that the concept of senses can be used in different ways. We might understand our senses to involve the input of perceptions of lived experience to our human consciousness, i.e. the 'now'. However, it is also possible for us to conceive of senses as those of the imagination and human emotions (e.g. as conceived by in contexts of art, emotional intelligence, etc.). Here, the senses are released from 'now' and can 'experience' the past or the future as well. Why is it difficult to connect reflection with use (or reflection on analysis with design practice)? This may be due to cultural and social aspects of our environments.

Figure 6 is an illustrator's view on the double bind in society (Hay, 2001). It shows marshmallows (representing individual

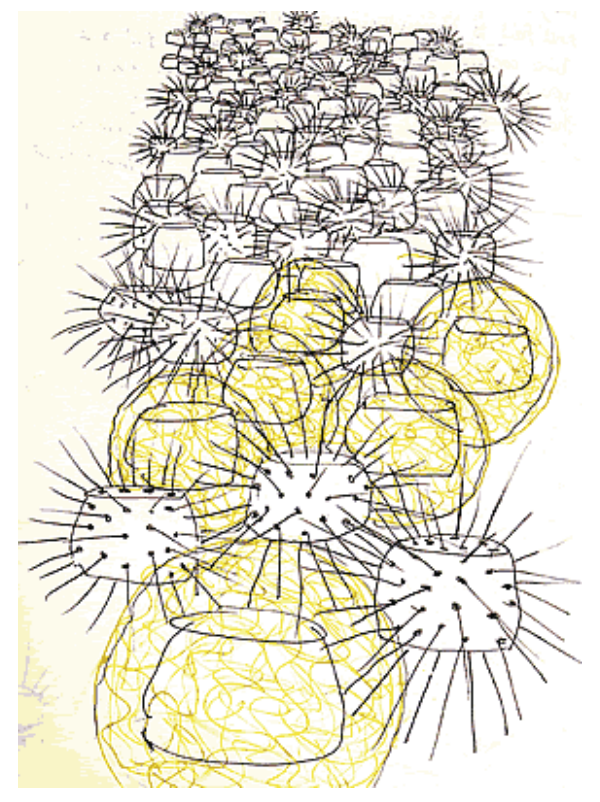

Figure 6: Society and Double Bind. (Hay, 2001) 
people) caught in a double bind. Each 'soft' marshmallow experiences 'pain' in its encounters with 'spiked' fellows. As a response, it grows spikes of its own. When marshmallows with spikes get together they are more prone to get stuck, reflecting entrapment. We can draw a parallel with entrapment of mind which can occur when human individuals espouse a paradigm equating to Bateson's first order learning and are not able to move beyond to embrace second order learning (e.g. reflection on thinking).

Individual emergence could mean unraveling entrapment through the identification of double binds and 'mixed messages', in short the re-learning of leveling patterns of communication and there is an irony that this can be done through therapy using double-binds' (Hay, 2001).

Hence, efforts at reflection on ones own behavior from an observer's stance might break into this cycle of harmful responses and encourage a beneficial dialogue. This can be viewed as breaking away from a single helix of experience, interpretation and reflection.

In both the examples discussed above, we can see how individual understandings, and reflection over these understandings, are continually changing in interaction with other people as time goes by. It is for this reason that we highlight a need to consider multiple levels of contextual dependencies. We might also consider, paraphrasing Heidegger's words, that inquiry into usability and usefulness has meaning only for the particular subject who judges (e.g. Heidegger, 1962).

\section{Conclusions}

In this paper, we explore the proposition that separation of (and confusion between) reflecting over use and usability, on one hand, and usefulness on the other, are open to question. We see support for this view in discussions such as that referred to in the 6th annual National Colloquium for Computer Security Education 2002:

Most representatives and speakers talked of information assurance programs at the bits and bytes level, with research agendas heavy on technology, including loss leaders like public-key infrastructure. And while speakers touted forensics programs, intrusion-detection and prevention programs, security standards development and other technical programs, there was little talk, about business value and critical thinking' (Radcliff, 2002). 
It appears that there were a few individual speakers, such as Professor Nimal Jayaratna, who deviated from the main stream and suggested that ' $W$ e need a fundamental re-think about security education issues'. Some educators, like Alexander Korzyk 'questioned whether information security should remain in the computer science discipline at all or be moved to areas of study more reflective of business risk issues' (Radcliff, 2002)

This is to us another example of the great importance we ascribe to reflecting on overall usefulness from end users' points of view. However, it is not obvious how reflecting would be encouraged in practice. We believe that the metaphor of the double helix described in this paper, may provide a vehicle for discussion - a step in the right direction.

In this paper, the authors have attempted to draw a distinction between the dialectic relationship of experiencing and designing of artifacts/processes, such as communication and information technology devices, and the more complex relationship which must be surmised to subsist between use and design in informing systems. We have done this by highlighting differences between the terms use, usability and usefulness in this context. The inherent complexity of such processes is a function of the nature of informing systems as a special case of a human activity system, in which people form an essential part of the system itself. The double helix metaphor is considered by the authors to be helpful as a means to examine complexities in such a relationship. The contribution of this paper is to support systems analysts in their efforts to cognize, and to recognize, continuities of experience and reflections upon experience in their practical inquiries.

From a philosophical perspective, the authors have highlighted the importance of a hermeneutically-informed, phenomenological approach as a means to challenge presuppositions which might be taken for granted. Such an approach also helps us to avoid a fallacious emphasis on objectivity, which is inappropriate when examining individual reflections on experiences (use of the plural 'experiences' here is intended to emphasize the uniqueness of individual perspectives). Dangers involved in an artificial separation between observations made and the unique perspectives of observers, leading to a loss of critical awareness are also highlighted. Methods of inquiry based in multiple levels of contextual inquiry are suggested as a means to empower individuals to reflect upon their experiences of use. In developing informing systems, they need to consider not just what and how and on whose behalf, but also the 
why, and from whose point of view - as this reflects the difference that makes a difference.

We have introduced two examples of approaches to inquiry into human activity systems which draw upon hermeneutically-informed, phenomenological perspectives. These are the Strategic Systemic Thinking Framework (Bednar, 2000) and image as a therapeutic catalyst (Hay, 2007). Both of these exemplify efforts to put critical systemic thinking into practice, influenced by work by Gregory Bateson.

Individual and collective sense-making processes are discussed in relation to learning about experiencing use in relation to designing. The authors discuss a need to go beyond the concept of the 'hermeneutic circle'. We discuss how an individual gradually reviews her own preunderstandings, with the support of experience, in a continual exchange/interchange between those pre-understandings and experience. Additionally, it is necessary to include interactions between individuals as a part of the analytical process. A recognition that people are reflecting and experiencing in interaction with other people (who are also reflecting and experiencing) supports awareness of a double hermeneutic through which a dialectic emerges. It is only through this recognition that critically-informed, systemic inquiry is enabled to progress. We perceive the phenomenon of a continuing flow of human experiencing and reflecting, not as a circle, but as a multifaceted spiral of learning about, and experience of, use, usability and usefulness over time.

\section{References}

Argyris, C. (1990). Overcoming organizational defenses: Facilitating organizational learning. Englewood Cliffs, NJ: Prentice Hall.

Argyris, C., \& Schon, D. (1979). Organizational learning. Reading, MA: Addison Wesley.

Bateson G. (1972). Steps to an ecology of mind. New York: Ballantine.

Bednar P. M. (2000). A contextual integration of individual and organizational learning perspectives as part of IS analysis. Informing Science Journal, 3(3), 145-156. Retrieved from http://inform.nu/Articles/Vol3/v3n3p145156.pdf

Bednar, P.M. (2001). Individual emergence in contextual analysis. Problems of Individual Emergence: $12^{\text {th }}$ biannual Problems of...' Systems Conference, Amsterdam, April 16-20. 
Bednar, P. M., \& Mallalieu, G. M. (2001). Romancing the stone: Play between romance and affection. EGOS $17^{\text {th }}$ Colloquium, The Odyssey of Organising, Lyon, France, 5-7 July.

Bednar, P. M., \& Welch, C. (2005). IS, process, organisational change and their relationship with contextual dependencies. Proceedings of ECIS 2005, Regensburg, Germany, 26-28 May.

Berger, P. L., \& Luckman, T. (1967). The social construction of reality: A treatise in the sociology of knowledge. Anchor Books.

Bijker, N. E., Hughes, T. P., \& Pinch, T. J. (Eds). (1987). The social construction of technological systems. MIT Press.

Checkland, P., \& Holwell, S. (1998). Information, systems and information systems: making sense of the field. Chichester: Wiley.

Ciborra, C.U. (1992). From thinking to tinkering: The grassroots of strategic information systems. Information Society, 8, 297-309.

Ciborra, C. (2002). The Labyrinths of information. Oxford University Press

Dervin, B. (1983) An overview of sense-making research: concepts, methods, and results to date. Paper presented at International Communication Association annual meeting, Dallas, May 1983.

Dervin, B. (1989). Audience as listener and learner, teacher and confidante: The sense-making approach. In R. Rice \& C. Atkin (Eds.), Public Communication Campaigns (2nd ed.). The United States of America: Sage Publications.

Ehn, P (1993). Skandinavian design: On participation and skill. In D. N. Schuler, \& N. Aki (Eds.), Participatory design: Principles and practice (Chapter 4, pp. 41-77). Lawrence Erlbaum.

Hay, N. (2001). Problems of individual emergence. Retrieved November 2006 from http://www.envf.port.ac.uk/illustration/images/vlsh/pieindex.htm

Hay, N. (2007 May). Image as a therapeutic catalyst. The Systemist, 29(1).

Heidegger, M. (1962). Gelassenheit. Stuttgart: Neske

Hirschheim, R., Klein, H. K., \& Lyytinen, K. (1995). Information systems development and data modelling: Conceptual and philosophical foundations. Cambridge: Cambridge University Press.

Husserl, E. (1970). The crisis of European sciences and transcendental philosophy: An introduction to phenomenological philosophy (D. Carr, Trans.). Evanston, IL: Northwestern University Press. Originally published 1954 in German, Walter Biernel (editor). 
Klein, H. K. (2006). The phenomenological and hermeneutic "Turns": The significance of Husserl's, Schutz' and Gadamer's ideas for information systems research. Third Leverhulme Lecture, University of Salford, Informatics Research Institute, $15^{\text {th }}$ November.

Langefors, B. (1966). Theoretical analysis of information systems. Lund, Sweden: Studentlitteratur.

Mackay, H. (1995). Theorising the IT/society relationship. In N. Heap, R. Thomas, G. Einon, \& H. Mackay (Eds.), Information technology and society (pp 41-53). Open University Press/Sage.

Maturana, H., \&Varela, F. (1992). The tree of knowledge: The biological roots of buman understanding. Boston: Shambhala.

Mumford, E. (2003). Redesigning human systems. London: IRM Press.

Mumford, E., Hirshheim, R., Fitzgerald, G., \& Wood-Harper, A. T. (Eds.). (1984). Research methods in information systems. Proceedings of the IFIP WG 8.2 Colloquium, Manchester Business School, North Holland, Amsterdam.

Nissen, H-E. (1984). Acquiring knowledge of information systems - Research in a methodological quagmire. In E. Mumford, R. Hirshheim, G. Fitzgerald, \& A. T. Wood-Harper (Eds.), Research methods in information systems. Proceedings of the IFIP WG 8.2 Colloquium, Manchester Business School (pp 39-52). North Holland, Amsterdam.

Nissen, H-E. (in this monograph). Double helix relationships of use, redesign and understanding of information systems. Informing Science Journal, Special Series.

Radcliff, D. (2002 June 05). Clarke warns educators about need for better security. Computerworld: Security. Retrieved from http://computerworld.com/securitytopics/security/story/0,10801,71714, 00.html

Radnitzky, G. (1970). Contemporary schools of metascience (2nd ed.). Gothenburg: Akademiforlaget.

Sauer, C. (1993). Why information systems fail: A case study approach. Oxfordshire: Alfred Waller.

Thurén, T. (1991). Vetenskapsteori för nybörjare. [Theory of science for beginners]. Stockholm: Runa Förlag (in Swedish).

Ulrich, W. (2001). Critically systemic discourse: A discursive approach to reflective practice in ISD, Parts $1 \& 2$. The Journal of Information Technology Theory and Application (JITTA), 3(3), 55-106. 
Ulrich, W. (2006). Rethinking critically reflective research practice: Beyond Popper's critical rationalism. Journal of Research Practice, 2(2), Article P1. Retrieved 26 June 2007, from

http://jrp.icaap.org/index.php/jrp/article/view/64/63

Vickers, G. (1965). The art of judgment. London: Methuen

Wagner, H. R. (Ed.). (1970). Alfred Schutz on phenomenology and social relations: Selected readings. University of Chicago Press

Walsham, G (1993). Interpreting information systems in organisations. Chichester: John Wiley \& Sons.

Weick, K. (1995). Sense making in organizations. Sage.

\section{Biographies}

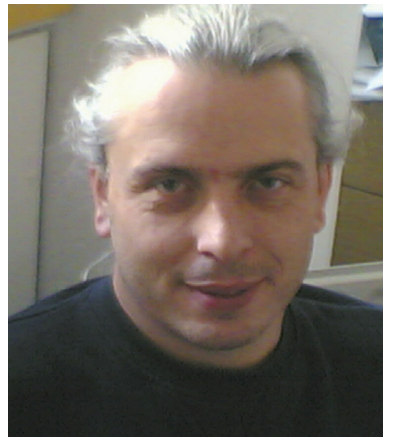

Peter M Bednar is an Engineer and Senior Lecturer. Since 1997, he has been working as an academic. His research covers contextual analysis, organizational change and information systems development, and he has published several book chapters and many articles in these fields. He is currently a member of the Information Systems group in the School of Computing at the University of Portsmouth, UK and is also affiliated to the Department of Informatics at Lund University, Sweden.

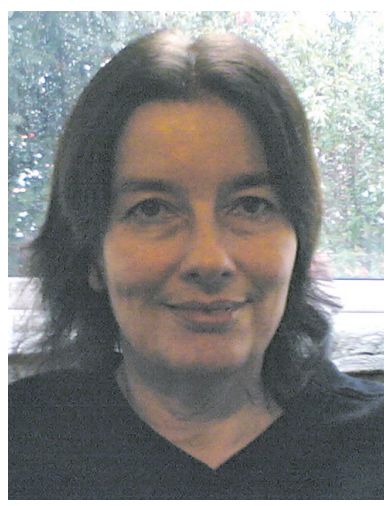

Christine Welch is a Principal Lecturer in the Department of Strategy and Business Systems, part of the Business School at the University of Portsmouth, UK. Her research interests include critical systemic thinking, contextual analysis and organizational change, and she has published several book chapters and articles in these fields. She is convener of the Southern Regional Centre of the UK Systems Society. 